\title{
AMIC for traumatic focal osteochondral defect of the talar shoulder: a 5 years follow-up prospective cohort study
}

\author{
Christian Götze ${ }^{1}$, Christian Nieder ${ }^{1}$, Hanna Felder ${ }^{1}$, Christian Dominik Peterlein ${ }^{1}$ and Filippo Migliorini ${ }^{2,33^{*}}$ (i)
}

\begin{abstract}
Background: Autologous Matrix-Induced Chondrogenesis (AMIC) is addressed to osteochondral defects of the talus. However, evidence concerning the midterm efficacy and safety of AMIC are limited. This study assessed reliability and feasibility of AMIC at 60 months follow-up. We hypothesize that AMIC leads to good clinical outcome at midterm follow-up.
\end{abstract}

Methods: Surgeries were approached with an arthrotomy via malleolar osteotomy. A resorbable porcine I/III collagen membrane (Chondro-Gide ${ }^{\circledR}$, Geistlich Pharma AG, Wolhusen, Switzerland) was used. Patients were followed at 24 and 60 months. The primary outcome of interest was to analyse the Foot Function Index (FFI), and the subscale hindfoot of the American Orthopaedic Foot and Ankle Score (AOFAS). Complications such as failure, revision surgeries, graft delamination, and hypertrophy were also recorded. The secondary outcome of interest was to investigate the association between the clinical outcome and patient characteristics at admission.

Results: Data from 19 patients were included. The mean age at admission was $47.3 \pm 13.2$ years, and the mean BMI $24.1 \pm 4.9 \mathrm{~kg} / \mathrm{m}^{2} .53 \%$ (10 of 19 patients) were female. At a mean of $66.2 \pm 11.6$ months, the FFI decreased at 24-months follow-up of 22.5\% ( $P=0.003)$ and of further $1.3 \%(P=0.8)$ at 60-months follow-up. AOFAS increased at 24-months follow-up of $17.2 \%(P=0.003)$ and of further $3.4(P=0.2)$ at 60 -months follow-up. There were two symptomatic recurrences within the follow-up in two patients. There was evidence of a strong positive association between FFI and AOFAS at baseline and the same scores last follow-up ( $P=0.001$ and $P=0.0002$, respectively).

Conclusion: AMIC enhanced with cancellous bone graft demonstrated efficacy and feasibility for osteochondral defects of the talus at five years follow-up. The greatest improvement was evidenced within the first two years. These results suggest that clinical outcome is influenced by the preoperative status of the ankle. High quality studies involving a larger sample size are required to detect seldom complications and identify prognostic factors leading to better clinical outcome.

Level of evidence: II, prospective cohort study.

Keywords: Talus, Osteochondral defects, AMIC

*Correspondence: migliorini.md@gmail.com

2 Department of Orthopaedics and Trauma Surgery, University Clinic Aachen, RWTH Aachen University Clinic, 52064 Aachen, Germany

Full list of author information is available at the end of the article

\section{Introduction}

Up to $50 \%$ of patients who experienced an acute ankle sprain demonstrated chondral damage [1]. If left untreated talar chondral defects can lead to early onset osteoarthritis [2]. Several surgical strategies have been addressed to chondral defects of the talus [3]. In 2005, original author(s) and the source, provide a link to the Creative Commons licence, and indicate if changes were made. The images or other third party material in this article are included in the article's Creative Commons licence, unless indicated otherwise in a credit line to the material. If material is not included in the article's Creative Commons licence and your intended use is not permitted by statutory regulation or exceeds the permitted use, you will need to obtain permission directly from the copyright holder. To view a copy of this licence, visit http://creativecommons.org/licenses/by/4.0/. The Creative Commons Public Domain Dedication waiver (http://creativeco mmons.org/publicdomain/zero/1.0/) applies to the data made available in this article, unless otherwise stated in a credit line to the data. 
Behrens et al. [4] described an enhanced microfractures technique wihch later has developed into the Autologous Matrix-Induced Chondrogenesis (AMIC). AMIC is a one-step surgical strategy which exploit the potential of autologous bone marrow-derived mesenchymal stem cells (BM-MSCs) [5, 6]. During AMIC the chondral defect is debrided until viable shoulders are achieved. Afterwards, bone marrow stimulation is performed to promote subchondral BM-MSCs migration in the chondral layer [7, 8]. A cell-free resorbable membrane is then trimmed and ensured over the defect, to create a blood clot rich in stem cells [9]. Several studies which focused on AMIC for chondral defects of the talus demonstrated high rate of patient satisfaction [10-24]. However, evidence concerning the midterm efficacy and safety of AMIC are limited. Recently, we published our results of AMIC on a cohort of 24 patients for chondral defects of the talus [5]. At 24 months follow-up all the patient reported outcome measures (PROMs) were significantly improved over their minimal clinically important difference (MCID). No patient experienced a complication. The present study assessed reliability and feasibility of AMIC on the same cohort of patients at 60 months follow-up. We hypothesize that AMIC leads to good clinical outcome at midterm follow-up.

\section{Material and methods}

\section{Study Design}

The present study was conducted according to the Consolidated Standards of Reporting Trials: the CONSORT statement [25]. The procedures reported in the present investigation were approved by the Ethics Committee of the Medical Faculty of the Ruhr University of Bochum, Germany (EK 2017-164). This study has been conducted according to the principles expressed in the Declaration of Helsinki. All patients were able to understand the nature of their treatment and provided written consent to use their clinical and imaging data for research purposes.

\section{Eligibility criteria}

In the period 2013 until 2016 all patients who underwent AMIC as management for osteochondral defects of the talar shoulder were enrolled prospectively. Patients were recruited at the Auguste Viktoria Clinic in Bad Oeynhausen, Germany. The inclusion criteria were: (1) symptomatic chronic ankle pain, (2) previous failed conservative management, (3) evidence of osteochondral defect of the talar shoulder on MR, (4) focal defect, (5) traumatic onset, (6) lesion $>1.0 \mathrm{~cm}^{2}$ (7) patients aged 18 to 65 years, (8) minimum 60 months follow-up. The exclusion criteria were: (1) metabolic arthropathies, (2) kissing lesions, (3) large non-reconstructable defects, (4) uncorrectable axial deformity, (5) chronic inflammatory systemic disease, (6) body mass index (BMI) $>30 \mathrm{~kg} / \mathrm{m}^{2}$, (7) bilateral ailments.

\section{Surgical technique}

All the surgeries were performed in the same fashion by two surgeons $(\mathrm{CG}, \mathrm{CN})$ who were well beyond their learning curve. The surgical procedure was performed in isolation in a standardized fashion [5]. Briefly, all patients were approached with an arthrotomy via malleolar osteotomy. The osteochondral lesions were identified and debrided from the avital tissue until a viable shoulder was reached. Subchondral defect was filled with autologous cancellous bone graft harvested from the osteotomy site or from the ipsilateral iliac crest. An aluminium template was trimmed according to the lesion size. A type resorbable porcine I/III collagen membrane (ChondroGide $^{\circledR}$, Geistlich Pharma AG, Wolhusen, Switzerland) was trimmed according to the aluminum template and hydrated in a saline solution. Microfractures of $4 \mathrm{~mm}$ depth were performed into the defect using 1.2- or 1.4$\mathrm{mm} \mathrm{K}$-wire under constant irrigation to avoid thermal necrosis. Afterwards, the membrane was placed into the defect and glued with fibrin (Tisseel, Baxter $\mathrm{GmbH}$, Germany) to ensure fixation. Osteotomy was fixed with two malleolar screws. For the first six postoperative weeks patients were invited to wear a vacopedis boot, weight-bearing on the operated ankle was not allowed, and started passive range of motion exercises. After six weeks, patients started an intensive rehabilitation program, gradually increasing the weight load to full bearing, strengthening of the lower leg muscles, and proprioception training.

\section{Outcomes of interest}

Patient baseline was recorded at admission: age, gender, side, size of defect, BMI, duration of symptoms. Patients were followed at 24 and 60 months. The primary outcome of interest was to analyse the Foot Function Index (FFI) [26], and the subscale hindfoot of the American Orthopaedic Foot and Ankle Score (AOFAS) [27]. Complications such as failure, revision surgeries, graft delamination, and hypertrophy were also recorded. Failure was defined as persistent pain which affects negatively the quality of life, limiting the participation to recreational activities. The secondary outcome of interest was to investigate the association between the clinical outcome and patient characteristics at admission.

\section{Statistical analysis}

All statistical analyses were performed by one author (FM). The software STATA/MP 14.1 (StataCorp, College Station, TX) was used for the analyses. The Saphiro-Wilk test was performed to investigate data distribution. Mean 
and standard deviation (SD) were adopted for parametric data, with Student $t$ test to assess significancy. For nonparametric data, median and interquartile range (IQR) were used, with Mann-Whitney U test for the significancy. A multivariate analysis was performed to assess associations between FFI and AOFAS at baseline and at last follow-up. A multiple linear model regression analysis using the Pearson Product-Moment Correlation Coefficient $(r)$ was used. According to the Cauchy-Schwarz formula values of $r$ tending to +1 were considered as positive linear correlation and those to -1 as negative. Values of $0.1<|r|<0.3,0.3<|r|<0.5$, and $|r|>0.5$ were considered to have respectively weak, moderate, and strong correlation. The overall significance was performed through the $X^{2}$ test. Values of $P<0.05$ were considered statistically significant.

\section{Results}

\section{Recruitment process}

A total of 65 patients were enrolled. Further 15 patients were not eligible: kissing lesions (3), large non-reconstructable defects (3), uncorrectable axial deformity (1), chronic inflammatory systemic disease (2), BMI $>30 \mathrm{~kg} /$ $\mathrm{m}^{2}$ (2), bilateral ailments (1). 50 patients underwent AMIC in the period 2013-2016. At 24-months follow-up, 26 patients were not eligible: change of residence $(N=4)$, died $(N=2)$, not wish to participate in the study $(N=20)$. At 60 months follow-up, five patients were no more traceable. Finally, 19 patients were analysed at 60 months follow-up. The flow-chart of the recruitment process is shown in Fig. 1.

\section{Patient demographics}

The mean length of the follow-up was $66.2 \pm 11.6$ months. The mean length of symptoms before the surgical intervention was $21.9 \pm 30.3$ months. The mean age at admission was $47.3 \pm 13.2$ years and the mean BMI $24.1 \pm 4.9 \mathrm{~kg} / \mathrm{m}^{2} .53 \%$ (10 of 19 patients) were female. The left side was involved in $37 \%$ (7 of 19) of patients. All lesions were located along the medial shoulder. The mean defect size was $6.9 \pm 2.2 \mathrm{~cm}^{2}$. Study demographic of is shown in Table 1.

\section{Outcomes of interest}

FFI decreased at 24-months follow-up of 22.5\% $(P=0.003)$ and of further $1.3 \%(P=0.8)$ at 60 -months follow-up (Table 2).

AOFAS increased at 24-months follow-up of $17.2 \%$ $(P=0.003)$ and of further 3.4 $(P=0.2)$ at 60 -months follow-up (Table 3). The Fig. 2 shows the box plots of the FFI and AOFAS scores.

There were two failures in two females. Both patients evidenced on MRI a recurrence of chondral defect. One patient underwent a further AMIC at three years postoperatively due to growing ankle pain. At last follow-up she declared herself satisfied with the surgery. Another patient complained growing ankle pain and is currently waiting for a revision surgery.

The multivariate analysis evidenced a strong positive association between FFI at baseline vs 24 months followup $(r=0.9 ; P<0.0001)$, baseline vs 60 months follow-up $(r=0.7 ; P=0.001), 24$ vs 60 months follow-up $(r=0.7$; $P=0.002)$. The AOFAS at baseline demonstrated a strong positive association with the AOFAS at 24 months follow-up ( $r=0.7 ; P=0.0008), 60$ months follow-up $(r=0.8$; $P=0.0002)$, and between 24 vs 60 months follow-up $(r=0.7 ; P=0.002)$. These results are shown in greater detail in Table 4.

\section{Discussion}

According to the main findings of the present study, AMIC enhanced with cancellous bone graft demonstrated efficacy and feasibility for osteochondral defects of the talus. The greatest efficacy was evidenced within the first two years, and no further difference was found from two to five years follow-up. Moreover, results of the present study suggest that clinical outcome is strongly influenced by the preoperative status of the ankle.

Several surgical strategies have been addressed to manage chondral defects of the talus [28, 29]. Isolated bone marrow stimulation (e.g. microfractures) is performed for smaller defects $[9,30,31]$. Microfractures are of simple execution, cost-effective, and achieved in a fully arthroscopic fashion. For bigger defects, osteochondral autograft transplantation has been widely performed [32, 33]. Osteochondral allograft transplantation has been introduced to avoid chondrocytes harvesting [34-36]. However, osteochondral allograft transplantation evidenced higher costs and rate of failure [37-40]. Autologous chondral transplantation (ACI) has been widely addressed to talar chondral defects [41, 42]. However, ACI requires a harvest site, two surgical sessions, and external chondrocytes expansion [43, 44]. Differently, AMIC is a single session strategy which spares chondrocytes harvesting and avoids cell expansion, exploiting the regenerative potential of BM-MSCs [5, 45]. These features commit AMIC of special interest of both patients and surgeons. Several studies showed promising results of AMIC for talar chondral defects, with high patient satisfaction and quick return to sport [10-24]. We identified only three long term studies investigating efficacy and feasibility of AMIC [12, 15, 21]. Becher et al. [12] in their clinical study followed 13 patients during five years follow-up. They reported a considerable reduction of the visual analogue scale (VAS) and improvement of the Hannover Scoring System. Furthermore, comparing 


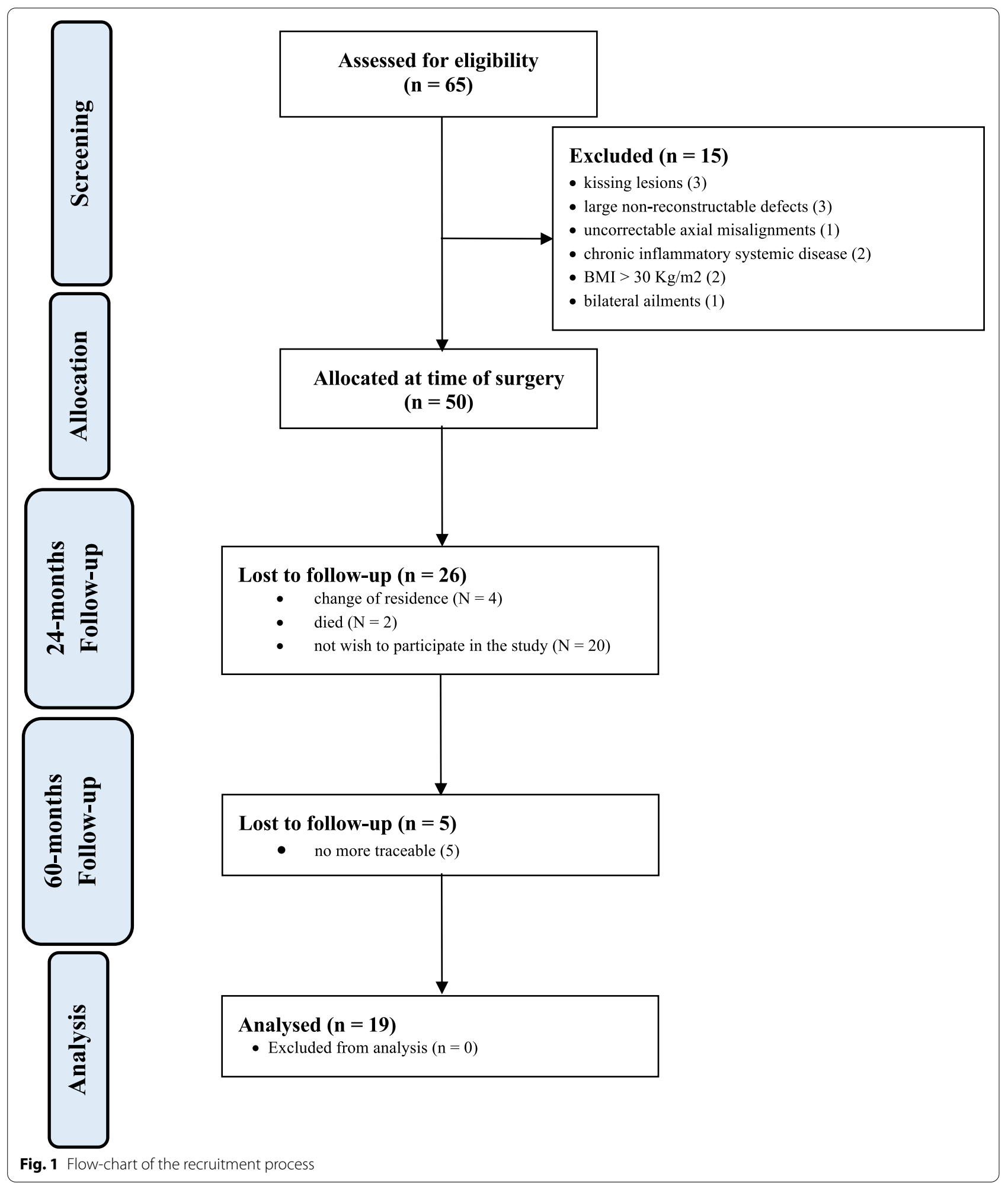

AMIC with a matched group of patients who underwent isolated bone marrow stimulation, they evidenced no difference at five years follow-up [12]. Weigelt et al. [21] evaluated AMIC on a cohort of 33 patients at 4.7 years follow-up. At last follow-up the AOFAS scored 93/100 and the VAS (0-10) 1.4/10 [21]. They reported one case 
Table 1 Demographic of the patients at baseline

\begin{tabular}{ll}
\hline Endpoint & Value at baseline \\
\hline Number of procedures & 19 \\
Mean age & $47.3 \pm 13.2$ \\
Female gender & $53 \%(10$ of 19) \\
Left side & $37 \%(7$ of 19) \\
Mean BMl & $24.1 \pm 4.9$ \\
Mean defect size $\left(\mathrm{cm}^{2}\right)$ & $6.9 \pm 2.2$ \\
Mean duration of prior symptoms (months) & $21.9 \pm 30.3$ \\
Mean length of follow up (months) & $66.2 \pm 11.6$ \\
\hline
\end{tabular}

Table 2 Results of FFI

\begin{tabular}{|c|c|c|c|c|c|c|c|c|}
\hline \multicolumn{3}{|c|}{ Baseline - 24 months } & \multicolumn{3}{|c|}{$24-60$ months } & \multicolumn{3}{|c|}{ Baseline - 60 months } \\
\hline MD & $95 \% \mathrm{Cl}$ & $P$ & MD & $95 \% \mathrm{Cl}$ & $P$ & MD & $95 \% \mathrm{Cl}$ & $P$ \\
\hline-22.5 & 8.064 to 36.936 & 0.003 & -1.3 & -12.110 to 14.710 & 0.8 & 23.8 & 11.343 to 36.257 & 0.0004 \\
\hline
\end{tabular}

Table 3 Results of AOFAS

\begin{tabular}{|c|c|c|c|c|c|c|c|c|}
\hline \multicolumn{3}{|c|}{ Baseline - 24 months } & \multicolumn{4}{|c|}{$24-60$ months } & \multicolumn{2}{|l|}{ Baseline -60 months } \\
\hline MD & $95 \% \mathrm{Cl}$ & $P$ & MD & $95 \% \mathrm{Cl}$ & $P$ & MD & $95 \% \mathrm{Cl}$ & $P$ \\
\hline 17.2 & $\begin{array}{c}28.222 \text { to } \\
6.178\end{array}$ & 0.003 & 3.4 & $\begin{array}{c}13.060 \text { to } \\
-6.260\end{array}$ & 0.5 & -17.2 & $\begin{array}{c}30.223 \text { to } \\
10.977\end{array}$ & 0.0001 \\
\hline
\end{tabular}

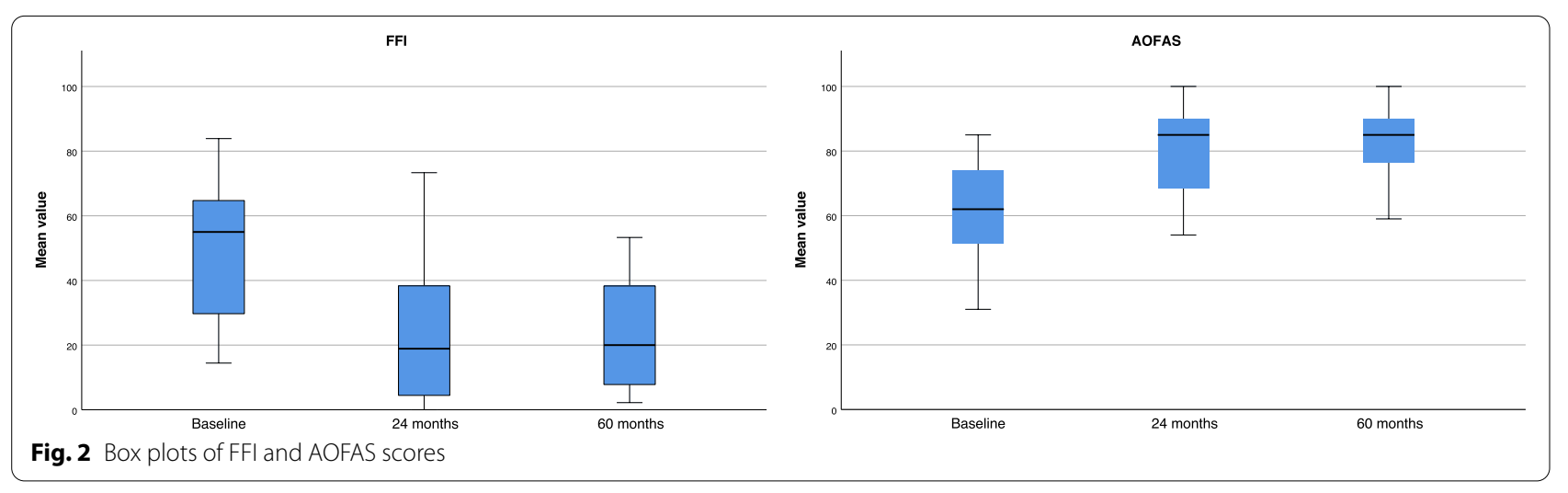

Table 4 Multivariate analyses

\begin{tabular}{|c|c|c|c|c|c|c|}
\hline \multirow[t]{2}{*}{ Endpoint } & \multicolumn{2}{|c|}{ Baseline -24 months } & \multicolumn{2}{|c|}{$24-60$ months } & \multicolumn{2}{|c|}{ Baseline -60 months } \\
\hline & $r$ & $P$ & $r$ & $P$ & $r$ & $P$ \\
\hline FFI & 0.9 & $<0.0001$ & 0.7 & 0.002 & 0.7 & 0.001 \\
\hline AOFAS & 0.7 & 0.0008 & 0.8 & 0.0002 & 0.7 & 0.002 \\
\hline
\end{tabular}


also evidenced by D'Ambrosi et al. [13] on 31 AMIC procedures. At two years follow-up they demonstrated an association between PROMs at baseline and the same at the follow-ups, concluding that the clinical results are strongly influenced by the preoperative status [13]. On the other hand, for patients with lesions of the central dome, the lesion size was proportionally associated with BMI, and that older patients had worse outcomes [46].

We used a malleolar osteotomy to distract the tibiotalar joint as standard. Malleolar osteotomy is associated to potential bony complications, loss of osteotomy reduction, delayed union or nonunion, symptomatic osteotomy site which may require removal $[47,48]$. The osteotomy might impair the articular surface: given the limited regenerative potential of cartilage, it may lead to premature osteoarthrosis of the tibiotalar joint. Tibiotalar distraction with plantar flexion and Hintermann spreader is also widely used to access the joint cavity. Although it allows to faster weightbearing and recovery, it may predispose to soft tissue damage, especially the neurovascular structures [49-55]. Whether malleolar osteotomy perform better than plantar flexion and Hintermann spreader has not yet been clarified.

Currently, cell therapies assembled in synthetic polymers are of special interest for chondral regeneration. Chondral procedures have been enhanced with cell therapies to improve their regenerative potential. Bone marrow aspirate concentrate has shown promising results in clinical and preclinical studies [56-61]. Mesenchymal stem cells have also been employed to augment chondral procedures with promising outcomes [62-66]. The current literature evidences a high ratio of preclinical to clinical studies on this topic, suggesting that we are in a transition phase to human application. Many synthetic polymers are currently available or under experimentation as potential scaffolds, such as polyglycolic acid (PGA), polylactic acid (PLA), polylactic-co-glycolic acid (PLGA) and polyethylene glycol-terephthalate/ polybutylene terephthalate (PEOT/PBT) $[67,68]$.

This study has several limitations. The limited number of patients and the lack of randomisation may have biased the conclusion. Another important limitation was the limited recruitment rate. Indeed, from 50 patients who initially underwent AMIC, only 19 were retrieved at five years follow-up. The institution in which the operations were conducted, is a well-known centre for orthopaedic surgery, thus attracting patients from the whole country. Therefore, many patients did not agree to engage a long trip for research purposes. Unfortunately, the last follow-up was conducted during the COVID pandemic, which has considerably limited patient adhesion and participation to the survey. Two patients were secondary and tertiary referrals to our centre. These patients were not aware of their previous treatments and they have no documentation. All the patients underwent previous conservative management; however, given the heterogeneous nature and/or the lack of documentation on the previous conservative management, it was not possible to analyse them in a separate fashion. In this respect, results may not be fully reliable. The lack of a control group and the unblinded design of the study represent additional limitations. These limitations affect considerably the reliability of the conclusions; therefore, results of the present study must be interpreted with caution. Further studies should investigate the potential of AMIC in a larger scale, comparing them with other more recently regenerative strategies, such as hydrogels or synthetic polymers [67-70].

\section{Conclusion}

AMIC enhanced with cancellous bone graft demonstrated efficacy and feasibility for osteochondral defects of the talus. The greatest improvement was evidenced within the first two years, and no further difference was found from two to five years follow-up. Moreover, results of the present study suggest that clinical outcome is strongly influenced by the preoperative status of the ankle.

\section{Abbreviations \\ AMIC: Autologous Matrix-Induced Chondrogenesis; FFI: Foot Function Index; AOFAS: American Orthopaedic Foot and Ankle Score; PROMs: Patient Report Outcome Measures; MRI: Magnetic Resonance Imaging; VAS: Visual Analogue Scale.}

\section{Acknowledgements}

This study represents a 5 years follow-up of a previous published study: Gotze C, Nieder C, Felder H, Migliorini F (2020) AMIC for Focal Osteochondral Defect of the Talar Shoulder. Life (Basel) 10 (12). doi: https://doi.org/10.3390/life10120328.

\section{Authors' contributions}

Conceptualization CG and CN; Methodology CG; Software FM; Validation, CG, CN, CDP and FM; Formal Analysis FM; Investigation CG, CDP; Resources CG and FM; Data Curation FM, CG, CN, CDP; Writing - Original Draft Preparation FM; Writing - Review \& Editing CG, CDP; Visualization FM, CG, CN, CDP, and HF; Supervision CG; Project Administration CG. FM and CDP have equally contributed to the completion of the present work and share the last position in the author list. The author(s) read and approved the final manuscript.

\section{Funding}

No external source of funding was used. Open Access funding enabled and organized by Projekt DEAL.

\section{Availability of data and materials}

All data generated or analysed during this study are included in this published article.

\section{Declarations}

Ethics approval and consent to participate

This study was approved by the Ethics Committee of the Medical Faculty of the Ruhr University of Bochum, Germany (EK 2017-164). All patients provided 
written informed consent to use their clinical and imaging data for research purposes.

\section{Consent for publication}

Not applicable.

\section{Competing interests}

The authors declare that they have no conflicts interest.

\section{Author details}

'Department of Orthopaedic Surgery, Auguste-Viktoria Clinic, Ruhr University Bochum, 32545 Bad Oeynhausen, Germany. ${ }^{2}$ Department of Orthopaedics and Trauma Surgery, University Clinic Aachen, RWTH Aachen University Clinic, 52064 Aachen, Germany. ${ }^{3}$ Department of Orthopaedicand Trauma Surgery, RWTH Aachen University Hospital, Pauwelsstraße 31, 52074 Aachen, Germany.

Received: 25 March 2021 Accepted: 3 July 2021

Published online: 24 July 2021

\section{References}

1. Murawski CD, Kennedy JG. Operative treatment of osteochondral lesions of the talus. J Bone Joint Surg Am. 2013;95(11):1045-54.

2. Mankin HJ. The response of articular cartilage to mechanical injury. J Bone Joint Surg Am. 1982;64(3):460-6.

3. Migliorini F, Berton A, Salvatore G, Candela V, Khan W, Longo UG, Denaro $V$. Autologous chondrocyte implantation and mesenchymal stem cells for the treatments of chondral defects of the knee- a systematic review. Curr Stem Cell Res Ther. 2020;15(6):547-56.

4. Behrens P. Matrixgekoppelte Mikrofrakturierung. Arthroskopie. 2005;18:193-7.

5. Gotze C, Nieder C, Felder H, Migliorini F. AMIC for focal osteochondral defect of the talar shoulder. Life (Basel). 2020;10(12):328

6. de Girolamo L, Schonhuber H, Vigano M, Bait C, Quaglia A, Thiebat G, Volpi P. Autologous Matrix-Induced Chondrogenesis (AMIC) and AMIC Enhanced by Autologous Concentrated Bone Marrow Aspirate (BMAC) allow for stable clinical and functional improvements at up to 9 years follow-up: results from a randomized controlled study. J Clin Med. 2019;21;8(3):392.

7. Schiavone Panni A, Del Regno C, Mazzitelli G, D'Apolito R, Corona K, Vasso M. Good clinical results with autologous matrix-induced chondrogenesis (Amic) technique in large knee chondral defects. Knee Surg Sports Traumatol Arthrosc. 2018:26(4):1130-6.

8. Schagemann J, Behrens P, Paech A, Riepenhof H, Kienast B, Mittelstadt $\mathrm{H}$, Gille J. Mid-term outcome of arthroscopic AMIC for the treatment of articular cartilage defects in the knee joint is equivalent to mini-open procedures. Arch Orthop Trauma Surg. 2018;138(6):819-25.

9. Anders S, Volz M, Frick H, Gellissen J. A Randomized, Controlled Trial Comparing Autologous Matrix-Induced Chondrogenesis (AMIC(R)) to Microfracture: analysis of 1- and 2-year follow-up data of 2 centers. Open Orthop J. 2013;7:133-43.

10. Albano D, Martinelli N, Bianchi A, Messina C, Malerba F, Sconfienza LM Clinical and imaging outcome of osteochondral lesions of the talus treated using autologous matrix-induced chondrogenesis technique with a biomimetic scaffold. BMC Musculoskelet Disord. 2017;18(1):306.

11. Baumfeld T, Baumfeld D, Prado M, Nery C. All-arthroscopic AMIC((R)) (ATAMIC) for the treatment of talar osteochondral defects: a short follow-up case series. Foot (Edinb). 2018;37:23-7.

12. Becher C, Malahias MA, Ali MM, Maffulli N, Thermann H. Arthroscopic microfracture vs. arthroscopic autologous matrix-induced chondrogenesis for the treatment of articular cartilage defects of the talus. Knee Surg Sports Traumatol Arthrosc. 2019;27(9):2731-6.

13. D’Ambrosi R, Maccario C, Serra N, Liuni F, Usuelli FG. Osteochondral lesions of the talus and autologous matrix-induced chondrogenesis: is age a negative predictor outcome? Arthroscopy. 2017;33(2):428-35.

14. Galla M, Duensing I, Kahn TL, Barg A. Open reconstruction with autologous spongiosa grafts and matrix-induced chondrogenesis for osteochondral lesions of the talus can be performed without medial malleolar osteotomy. Knee Surg Sports Traumatol Arthrosc. 2019;27(9):2789-95.
15. Gottschalk O, Altenberger S, Baumbach S, Kriegelstein S, Dreyer F, Mehlhorn A, Horterer H, Topfer A, Roser A, Walther M. Functional Medium-term results after autologous matrix-induced chondrogenesis for osteochondral lesions of the talus: a 5-year prospective cohort study. J Foot Ankle Surg. 2017:56(5):930-6.

16. Kretzschmar M, Bieri O, Miska M, Wiewiorski M, Hainc N, Valderrabano V, Studler U. Characterization of the collagen component of cartilage repair tissue of the talus with quantitative MRI: comparison of T2 relaxation time measurements with a diffusion-weighted double-echo steady-state sequence (dwDESS). Eur Radiol. 2015;25(4):980-6.

17. Kubosch EJ, Erdle B, Izadpanah K, Kubosch D, Uhl M, Sudkamp NP, Niemeyer P. Clinical outcome and T2 assessment following autologous matrix-induced chondrogenesis in osteochondral lesions of the talus. Int Orthop. 2016;40(1):65-71.

18. Richter M, Zech S, Meissner S, Naef I. Comparison Matrix-Associated Stem Cell Transplantation (MAST) with Autologous Matrix Induced Chondrogenesis plus Peripheral Blood Concentrate (AMIC+PBC) in chondral lesions at the ankle-A clinical matched-patient analysis. Foot Ankle Surg. 2020;26(6):669-75.

19. Usuelli FG, de Girolamo L, Grassi M, D'Ambrosi R, Montrasio UA, Boga M. All-arthroscopic autologous matrix-induced chondrogenesis for the treatment of osteochondral lesions of the talus. Arthrosc Tech. 2015;4(3):e255-259.

20. Valderrabano V, Miska M, Leumann A, Wiewiorski M. Reconstruction of osteochondral lesions of the talus with autologous spongiosa grafts and autologous matrix-induced chondrogenesis. Am J Sports Med. 2013;41(3):519-27.

21. Weigelt L, Hartmann R, Pfirrmann C, Espinosa N, Wirth SH. Autologous matrix-induced chondrogenesis for osteochondral lesions of the talus: a clinical and radiological 2- to 8-year follow-up study. Am J Sports Med. 2019;47(7):1679-86.

22. Wiewiorski M, Barg A, Valderrabano V. Autologous matrix-induced chondrogenesis in osteochondral lesions of the talus. Foot Ankle Clin. 2013;18(1):151-8.

23. Wiewiorski M, Werner L, Paul J, Anderson AE, Barg A, Valderrabano V. Sports Activity after reconstruction of osteochondral lesions of the talus with autologous spongiosa grafts and autologous matrix-induced chondrogenesis. Am J Sports Med. 2016;44(10):2651-8.

24. Yontar NS, Aslan L, Can A, Ogut T. One step treatment of talus osteochondral lesions with microfracture and cell free hyaluronic acid based scaffold combination. Acta Orthop Traumatol Turc. 2019;53(5):372-5.

25. Moher D, Hopewell S, Schulz KF, Montori V, Gotzsche PC, Devereaux PJ, Elbourne D, Egger M, Altman DG: CONSORT 2010 explanation and elaboration: updated guidelines for reporting parallel group randomised trials. BMJ 2010, 340:C869

26. Budiman-Mak E, Conrad KJ, Roach KE. The Foot Function Index: a measure of foot pain and disability. J Clin Epidemiol. 1991;44(6):561-70.

27. Kitaoka HB, Alexander IJ, Adelaar RS, Nunley JA, Myerson MS, Sanders M. Clinical rating systems for the ankle-hindfoot, midfoot, hallux, and lesser toes. Foot Ankle Int. 1994;15(7):349-53.

28. Park CH, Song KS, Kim JR, Lee SW. Retrospective evaluation of outcomes of bone peg fixation for osteochondral lesion of the talus. Bone Joint J. 2020:102-B(10):1349-53.

29. Sadlik B, Kolodziej L, Blasiak A, Szymczak M, Warchal B. Biological reconstruction of large osteochondral lesions of the talar dome with a modified "sandwich" technique-midterm results. Foot Ankle Surg. 2017;23(4):290-5.

30. Mundi R, Bedi A, Chow L, Crouch S, Simunovic N, SibilskyEnselman E, Ayeni OR. Cartilage restoration of the knee: a systematic review and meta-analysis of level 1 studies. Am J Sports Med. 2016;44(7):1888-95.

31. Valtanen RS, Arshi A, Kelley BV, Fabricant PD, Jones KJ. Articular cartilage repair of the pediatric and adolescent knee with regard to minimal clinically important difference: a systematic review. Cartilage. 2020;1 1(1):9-18.

32. Gomoll AH, Madry H, Knutsen G, van Dijk N, Seil R, Brittberg M, Kon E. The subchondral bone in articular cartilage repair: current problems in the surgical management. Knee Surg Sports Traumatol Arthrosc. 2010;18(4):434-47.

33. Godin JA, Sanchez G, Cinque ME, Chahla J, Kennedy NI, Provencher MT. Osteochondral allograft transplantation for treatment of medial femoral condyle defect. Arthrosc Tech. 2017;6(4):e1239-44. 
34. Czitrom AA, Keating S, Gross AE. The viability of articular cartilage in fresh osteochondral allografts after clinical transplantation. J Bone Joint Surg Am. 1990;72(4):574-81.

35. Williams SK, Amiel D, Ball ST, Allen RT, Tontz WL Jr, Emmerson BC, Badlan NM, Emery SC, Haghighi P, Bugbee WD. Analysis of cartilage tissue on a cellular level in fresh osteochondral allograft retrievals. Am J Sports Med. 2007;35(12):2022-32.

36. Sherman SL, Thyssen E, Nuelle CW. Osteochondral autologous transplantation. Clin Sports Med. 2017:36(3):489-500.

37. Gross AE, Agnidis Z, Hutchison CR. Osteochondral defects of the talus treated with fresh osteochondral allograft transplantation. Foot Ankle Int. 2001;22(5):385-91.

38. El-Rashidy H, Villacis D, Omar I, Kelikian AS. Fresh osteochondral allograft for the treatment of cartilage defects of the talus: a retrospective review. J Bone Joint Surg Am. 2011;93(17):1634-40.

39. Ahmad J, Jones K. Comparison of osteochondral autografts and allografts for treatment of recurrent or large talar osteochondral lesions. Foot Ankle Int. 2016;37(1):40-50.

40. Shimozono Y, Hurley ET, Nguyen JT, Deyer TW, Kennedy JG. Allograft compared with autograft in osteochondral transplantation for the treatment of osteochondral lesions of the talus. J Bone Joint Surg Am. 2018;100(21):1838-44.

41. Kreulen C, Giza E, Walton J, Sullivan M. Seven-year follow-up of matrixinduced autologous implantation in talus articular defects. Foot Ankle Spec. 2018;11(2):133-7.

42. Schneider TE, Karaikudi S. Matrix-Induced Autologous Chondrocyte Implantation (MACI) grafting for osteochondral lesions of the talus. Foot Ankle Int. 2009;30(9):810-4.

43. Pagliazzi G, Vannini F, Battaglia M, Ramponi L, Buda R. Autologous chondrocyte implantation for talar osteochondral lesions: comparison between 5-year follow-up magnetic resonance imaging findings and 7-year follow-up clinical results. J Foot Ankle Surg. 2018;57(2):221-5.

44. Dixon S, Harvey L, Baddour E, Janes G, Hardisty G. Functional outcome of matrix-associated autologous chondrocyte implantation in the ankle. Foot Ankle Int. 2011:32(4):368-74.

45. Gille J, Behrens P, Volpi P, de Girolamo L, Reiss E, Zoch W, Anders S. Outcome of Autologous Matrix Induced Chondrogenesis (AMIC) in cartilage knee surgery: data of the AMIC Registry. Arch Orthop Trauma Surg. 2013;133(1):87-93.

46. D'Ambrosi R, Maccario C, Serra N, Ursino C, Usuelli FG. Relationship between symptomatic osteochondral lesions of the talus and quality of life, body mass index, age, size and anatomic location. Foot Ankle Surg. 2018;24(4):365-72.

47. Lee KT, Kim JS, Young KW, Lee YK, Park YU, Kim YH, Cho HK. The use of fibrin matrix-mixed gel-type autologous chondrocyte implantation in the treatment for osteochondral lesions of the talus. Knee Surg Sports Traumatol Arthrosc. 2013:21(6):1251-60.

48. Leumann A, Horisberger M, Buettner O, Mueller-Gerbl M, Valderrabano V. Medial malleolar osteotomy for the treatment of talar osteochondral lesions: anatomical and morbidity considerations. Knee Surg Sports Traumatol Arthrosc. 2016;24(7):2133-9.

49. Zengerink M, van Dijk CN. Complications in ankle arthroscopy. Knee Surg Sports Traumatol Arthrosc. 2012:20(8):1420-31.

50. Amendola A, Petrik J, Webster-Bogaert S. Ankle arthroscopy: outcome in 79 consecutive patients. Arthroscopy. 1996:12(5):565-73.

51. Barber FA, Click J, Britt BT. Complications of ankle arthroscopy. Foot Ankle. 1990;10(5):263-6.

52. Bonnin M, Bouysset M. Arthroscopy of the ankle: analysis of results and indications on a series of 75 cases. Foot Ankle Int. 1999;20(11):744-51.

53. Cutsuries AM, Saltrick KR, Wagner J, Catanzariti AR. Arthroscopic arthroplasty of the ankle joint. Clin Podiatr Med Surg. 1994;11(3):449-67.
54. Ferkel RD, Small HN, Gittins JE. Complications in foot and ankle arthroscopy. Clin Orthop Relat Res. 2001;391:89-104.

55. Frey C, Feder KS, DiGiovanni C. Arthroscopic evaluation of the subtalar joint: does sinus tarsi syndrome exist? Foot Ankle Int. 1999;20(3):185-91.

56. Kim YS, Park EH, Kim YC, Koh YG. Clinical outcomes of mesenchymal stem cell injection with arthroscopic treatment in older patients with osteochondral lesions of the talus. Am J Sports Med. 2013;41(5):1090-9.

57. Koh YG, Choi YJ, Kwon OR, Kim YS. Second-look arthroscopic evaluation of cartilage lesions after mesenchymal stem cell implantation in osteoarthritic knees. Am J Sports Med. 2014;42(7):1628-37.

58. Koh YG, Jo SB, Kwon OR, Suh DS, Lee SW, Park SH, Choi YJ. Mesenchymal stem cell injections improve symptoms of knee osteoarthritis. Arthroscopy. 2013;29(4):748-55.

59. Haleem AM, Singergy AA, Sabry D, Atta HM, Rashed LA, Chu CR, El Shewy MT, Azzam A, Abdel Aziz MT. The clinical use of human culture-expanded autologous bone marrow mesenchymal stem cells transplanted on platelet-rich fibrin glue in the treatment of articular cartilage defects: a pilot study and preliminary results. Cartilage. 2010;1(4):253-61.

60. Miljkovic ND, Cooper GM, Marra KG. Chondrogenesis, bone morphogenetic protein-4 and mesenchymal stem cells. Osteoarthritis Cartilage. 2008;16(10):1121-30.

61. Anderson JA, Little D, Toth AP, Moorman CT 3rd, Tucker BS, Ciccotti MG, Guilak F. Stem cell therapies for knee cartilage repair: the current status of preclinical and clinical studies. Am J Sports Med. 2014;42(9):2253-61.

62. Wakitani S, Imoto K, Yamamoto T, Saito M, Murata N, Yoneda M. Human autologous culture expanded bone marrow mesenchymal cell transplantation for repair of cartilage defects in osteoarthritic knees. Osteoarthritis Cartilage. 2002;10(3):199-206.

63. Gobbi A, Karnatzikos G, Scotti C, Mahajan V, Mazzucco L, Grigolo B. Onestep cartilage repair with bone marrow aspirate concentrated cells and collagen matrix in full-thickness knee cartilage lesions: results at 2-year follow-up. Cartilage. 2011;2(3):286-99.

64. Gobbi A, Karnatzikos G, Sankineani SR. One-step surgery with multipotent stem cells for the treatment of large full-thickness chondral defects of the knee. Am J Sports Med. 2014;42(3):648-57.

65. de Windt TS, Vonk LA, Slaper-Cortenbach IC, van den Broek MP, Nizak R, van Rijen MH, de Weger RA, Dhert WJ, Saris DB. Allogeneic mesenchymal stem cells stimulate cartilage regeneration and are safe for single-stage cartilage repair in humans upon mixture with recycled autologous chondrons. Stem Cells. 2017;35(1):256-64.

66. Bonetti MA, Rovere G, Fulchignoni C, De Santis V, Ziranu A, Maccauro G, Pataia E. Autologous fat transplantation for the treatment of trapeziometacarpal joint osteoarthritis. Orthop Rev (Pavia). 2020;12(Suppl 1):8666.

67. Kwan H, Chisari E, Khan WS. Cell-free scaffolds as a monotherapy for focal chondral knee defects. Materials (Basel.) 202013(2):306.

68. Bekkers JE, Tsuchida AI, Malda J, Creemers LB, Castelein RJ, Saris DB, Dhert WJ. Quality of scaffold fixation in a human cadaver knee model. Osteoarthritis Cartilage. 2010;18(2):266-72.

69. Pipino G, Risitano S, Alviano F, Wu EJ, Bonsi L, Vaccarisi DC, Indelli PF. Microfractures and hydrogel scaffolds in the treatment of osteochondral knee defects: a clinical and histological evaluation. J Clin Orthop Trauma. 2019;10(1):67-75

70. Shah SS, Lee S, Mithoefer K: Next-generation marrow stimulation technology for cartilage repair: basic science to clinical application. JBJS Rev 2021, 9(1):e20 00090

\section{Publisher's Note}

Springer Nature remains neutral with regard to jurisdictional claims in published maps and institutional affiliations. 